\title{
A case of newly diagosed type 2 diabetes mellitus case with extremely elevated a1c and triglyceride levels
}

\author{
Atak BM, Aktas G*, Duman TT, Kocak MZ, Erkus E and Savli H \\ Abant Izzet Baysal University Hospital, Department of Internal Medicine, Bolu, Turkey
}

\begin{abstract}
Type 2 diabetes mellitus (DM) is a chronic metabolic disorder characterized with defects in insulin action. Glycated hemoglobin (A1c); a predictor of diabetic control, is used in follow up of the diabetic subjects. In this case report, we aimed to present a newly diagnosed type 2 diabetic subject with extremely high A1c and serum triglyceride levels. A 49-year-old man showed up to our clinic with complaints of weight loss due to good appetite, increased amount of micturition and increased sense of thirst. In serum analysis, his fasting plasma glucose was $494 \mathrm{mg} / \mathrm{dl}$, A1c was $19.8 \%$, and triglyceride was $4499 \mathrm{mg} / \mathrm{dl}$. With appropriate insulin and antihyperlipdemic treatment, his blood glucose and triglyceride reduced to less dangerous levels. In conclusion, since type 2 DM has an insidious onset, it can be present for years and develop hypertriglyceridemia and complications before establishment of the diagnosis. Therefore, screening DM in adults is strongly advised.
\end{abstract}

\section{Introduction}

Type 2 diabetes mellitus (DM) is a chronic metabolic disorder characterized with defects in insulin action. Prevalence of type $2 \mathrm{DM}$ is increasing by time in developed countries and causes a great economic burden in healthcare systems [1]. Glycated hemoglobin (A1c); a predictor of diabetic control, is used in follow up of the diabetic subjects. Initially, it is not suggested to be used as a diagnostic tool due to difficulties in standardization of Alc measurement. After evidences of its prognostic value accumulated, authors introduced the A1c as diagnostic and follow up tool in diabetic subjects.

Dyslipidemia is one of the major cardiac risk factors in diabetic population [2]. Hypertriglyceridemia, as a lipid metabolism disorder, is a consequence of overproduction or defective processing and clearance, or both. Treatment of hypertriglyceridemia is essential, since it is supposed as an independent risk factor for cardiovascular diseases, and moreover, it has important role in etiologies of non-biliary pancreatitis and non-alcoholic steatohepatitis [3].

In this case report, we aimed to present a newly diagnosed type 2 diabetic subject with extremely high A1c and serum triglyceride levels, and to review the literature.

\section{Case report}

A 49-year-old man showed up to our clinic with complaints of weight loss due to good appetite, increased amount of micturition and increased sense of thirst. His medical history was not relevant for any chronic diseases or use of any medication. His family history was positive for type $2 \mathrm{DM}$. On physical examination, his height was $164 \mathrm{~cm}$, weight was $78 \mathrm{~kg}$, waist circumference was $99 \mathrm{~cm}$. A body mass index was calculated as $29 \mathrm{~kg} / \mathrm{m}^{2}$. His systolic blood pressure was $130 \mathrm{mmHg}$ and diastolic blood pressure was $80 \mathrm{mmHg}$. Rest of the physical examination finding were normal.

A bundle of blood laboratory test results was as follows: fasting plasma glucose: $494 \mathrm{mg} / \mathrm{dl}$, Alc: $19.8 \%$, sodium: $122 \mathrm{meq} / \mathrm{l}$, triglyceride: $4499 \mathrm{mg} / \mathrm{dl}$, LDL-cholesterol: $172 \mathrm{mg} / \mathrm{dl}$, HDL-cholesterol: $25 \mathrm{mg} /$ dl. Other serum biochemistry was in normal range. Similarly, arterial blood gas analysis and urinalysis were normal.

He is diagnosed with type $2 \mathrm{DM}$ and intensive insulin treatment; 4 times a day, at a dose of $0.5 \mathrm{IU} / \mathrm{kg}$ initiated along with fenofibrate 267 $\mathrm{mg}$ and Atorvastatin $20 \mathrm{mg}$ daily. His blood glucose frequently checked and remained between $150-200 \mathrm{mg} / \mathrm{dl}$ during follow up. Abdominal examination and query (both history and serum biochemistry) performed in certain intervals since elevated triglyceride levels could cause pancreatitis. Abdominal sonography, serum amylase and lipase levels were normal. Diabetic retinopathy and lipemia retinalis were ruled out with eye examination. A 24 hours urine analysis revealed proteinuria at micro albuminuria level.

A coronary angiography performed due to non-specific chest pain and suspicious ST elevation in electrocardiogram. A $20 \%$ narrowness in left anterior descending artery revealed and cardiologists suggested medical treatment.

Before discharging from hospital, control serum triglyceride measurement performed. It was reduced to $680 \mathrm{mg} / \mathrm{dl}$. He remained symptom free during hospital stay and discharged from hospital at $7^{\text {th }}$ day, as his blood glucose measurements are in target. He was advised to use Metformin $1000 \mathrm{mg}$ twice a day plus subcutaneous insulin 4 times a day (preprandial short acting $20 \mathrm{IU}$ three times and $46 \mathrm{IU}$ basal insulin glargin).

\section{Discussion}

Due to insidious course of the disease subjects with undiagnosed type $2 \mathrm{DM}$ cases have serious complications when they refer to clinics.

Correspondence to: Gulali Aktas, M.D, Abant Izzet Baysal University Hospital, Department of Internal Medicine, Golkoy, 14280, Bolu, Turkey, Tel: +903742534656; E-mail: draliaktas@yahoo.com

Key words: Type 2 diabetes mellitus, A1c, hypertriglyceridemia

Received: January 14, 2018; Accepted: February 16, 2018; Published: February 19,2018 
Therefore, all complications should be screened when a patient is diagnosed with type $2 \mathrm{DM}$. Despite the fact that our case applied to a new diagnosis, the patient had entered a catabolic process; weight loss, polyuria and polydipsia symptoms occurred. HbAlc value of $19.8 \%$ was determined as a sign of poor metabolic control, in present case. In literature, Alc is considered as the most important predictor of metabolic control in DM and values of $13 \%$ and above are predict poor metabolic control [4-5]. Hyperglycemia along with hypertriglyceridemia and low HDL cholesterol lead a diagnosis of metabolic syndrome, however, his blood pressure was remained in normal range despite intravenous fluid replacement.

Hypertriglyceridemia is an important problem that must be kept in mind in the differential diagnosis of acute non-biliary pancreatitis. On the other hand, hypertriglyceridemia may also be a consequence of acute pancreatitis. Although the prevalence of hypertriglyceridemia in acute pancreatitis varies, edematous and necrotizing pancreatitis are have similar hypertriglyceridemia risk [6]. Both primary and secondary hypertriglyceridemia can lead to acute pancreatitis. Hypertriglyceridemia at levels of 500 to $1000 \mathrm{mg} / \mathrm{dL}$ may trigger acute pancreatitis [7]. Although the triglyceride level was extremely high $(4499 \mathrm{mg} / \mathrm{dl})$ in present case, the patient did not encounter with acute pancreatitis during hospital stay.

A lot of studies showed that main risk factors for development of cardiovascular complications are dyslipidemia, DM and obesity, components of metabolic syndrome. Atherogenic dyslipidemia is one of the interchangeable risk factors. Dyslipidemia, as a modifiable risk factor, should be managed with fibrates and statins in combination [8]. In our case, both fenofibrate and insulin treatments reduced triglyceride levels.

Risk factors for central retinal vein occlusion are somewhat similar to risk factors of cardiovascular diseases (eg, arteriosclerosis, arterial systemic hypertension, diabetes mellitus, and dyslipidemia) [9]. Therefore, we evaluated present case for eye complications by consulting with an ophthalmologist.

In conclusion, type $2 \mathrm{DM}$ is an insidious disease which has direct toxic effects on the arterial system. Before establishment of the diagnosis, it can be present for years and develop hypertriglyceridemia and complications. Therefore, screening DM in adults is strongly advised.

\section{References}

1. Shaw JE, Sicree RA, Zimmet PZ (2010) Global estimates of the prevalence of diabetes for 2010 and 2030. Diabetes research and clinical practice 87: 4-14. [Crossref]

2. Javadi E, Yarahmadi S, Larijani B, Mohammadi S-a, Shafaei A-R, et al. (2002) Prevalence of Dyslipidaemia in Diabetic Patients Attending The Diabetes Clinic A Doctor Shariati University Hospital Between October 1998 And September 2000. Iranian Journal of Diabetes and Metabolism 1: 133-137.

3. Burdick J, Tompwson M, Feldman M, Friadmen L, Brandt L, et al. (2006) Gastrointestinal and Liver Disease. Saunders Elsevier 1174-1184.

4. Mauras N, Merimee T, Rogol AD (1991) Function of the growth hormone-insulinlike growth factor I axis in the profoundly growth-retarded diabetic child: evidence for defective target organ responsiveness in the Mauriac syndrome. Metabolism 40: 1106-1111. [Crossref]

5. Simsek E, Kocabay K (2002) Insulin-like growth factor (IGF-I) in Mauriac syndrome or diabetic dwarfism. Turkish Journal Of Medical Sciences 32: 421-424.

6. Dominguez-Munoz J, Malfertheiner P, Ditschuneit H (1991) Hyperlipidemia in acute pancreatitis. International journal of pancreatology 10: 261-267. [Crossref]

7. Fortson MR, Freedman SN, Webster III PD. Clinical assessment of hyperlipidemic pancreatitis. American Journal of Gastroenterology 1995;90. [Crossref]

8. Millán JN, Pedro-Botet JM, Pintó XS (2014) Atherogenic dyslipidemia and residual risk. State of the art in 2014. Clinica e investigacion en arteriosclerosis: publicacion oficial de la Sociedad Espanola de Arteriosclerosis 26: 287-292.

9. Călugăru D (2011) Risk factors in central retinal vein occlusion. Oftalmologia 55 27-37.

Copyright: (C2018 Gulali A. This is an open-access article distributed under the terms of the Creative Commons Attribution License, which permits unrestricted use, distribution, and reproduction in any medium, provided the original author and source are credited. 